\title{
Mental Health Promotion and Illness Prevention: A Challenge for Psychiatrists
}

\author{
Jung-Ah Min, Chang-Uk Lee, and Chul Lee ${ }^{\bowtie}$ \\ Department of Psychiatry, Seoul St. Mary's Hospital, The Catholic University of Korea College of Medicine, Seoul, Republic of Korea
}

Mental health is essential for individual and public health. To improve mental health, promotion, prevention, and the treatment of disease are required. These three kinds of interventions are interrelated but independent from one another. Although separate efforts for mental health promotion and prevention are needed as well as the public need of mental health promotion and well-being, psychiatrists usually are not accustomed to mental health promotion and prevention. This review introduces an overview of the concept, subjects according to target populations, and various intervention strategies for mental health promotion and prevention of mental illnesses. Based on literatures to date, understanding of developmental psychology, lifestyle medicine, and biopsychosocial contributors of mental health with a macroscopic perspective might help to practice mental health promotion and illness prevention.

Psychiatry Investig 2013;10:307-316

Key Words Mental health, Health promotion, Primary prevention, Early intervention, Personal satisfaction.

\section{INTRODUCTION}

Health is defined as "a state of complete physical, mental, and social well-being and not merely an absence of disease or infirmity" by World Health Organization (WHO). ${ }^{1}$ To improve health, the promotion of health, prevention of disease, impairment, and disability, and the treatment of disease are required. However, the values of mental health promotion and illness prevention have been underappreciated more than those of physical health to date with regards to mental health. ${ }^{2}$ This is in line with that research on mental health has been weighted heavily on psychopathologies and mental illnesses rather than well-being or optimal functioning. ${ }^{3}$ Although separate strategies from treatment are needed for mental health promotion and prevention of mental illnesses, ${ }^{4}$ psychiatrists are not usually accustomed to these concepts and approaches. ${ }^{5}$

Indeed, subthreshold psychiatric symptoms, such as depression and anxiety, are reported in a large proportion of po-

Received: July 24, 2012 Revised: January 14, 2013

Accepted: March 5, 2013 Available online: December 16, 2013

$\triangle$ Correspondence: Chul Lee, MD, PhD

Department of Psychiatry, Seoul St. Mary's Hospital, The Catholic University of Korea College of Medicine, 222 Banpo-daero, Seocho-gu, Seoul 137-701, Republic of Korea

Tel: +82-2-2258-5443, Fax: +82-2-594-3870, E-mail: cle512@catholic.ac.kr

(a) This is an Open Access article distributed under the terms of the Creative Commons Attribution Non-Commercial License (http://creativecommons.org/licenses/bync/3.0) which permits unrestricted non-commercial use, distribution, and reproduction in any medium, provided the original work is properly cited. pulations. ${ }^{6}$ Although it is subthreshold in level, these symptoms often debilitate and increase the risk of occurring psychiatric disorder within a few years. ${ }^{7}$ Therefore, screening and early intervention of individuals at high risk are important issue in preventing mental illnesses.

However, mental health is not just the absence of mental illness but enjoyable, productive, and fulfilling life. ${ }^{8}$ This balanced optimal functioning of individuals should be the goal for mental health practitioners. Accordingly, 10-year cohort study showed that individuals with low positive well-being are at risk of developing depression. ${ }^{9}$ With the increase of individual and social needs for mental well-being and positive mental health, ${ }^{4,10,11}$ increasing resilience and well-being might provide the targets of primary or secondary prevention among otherwise healthy individuals. ${ }^{12}$ Moreover, the importance of positive well-being and resilience factors has also been suggested in clinical populations. While baseline high resilience predicted treatment response within six months in depressed patients, ${ }^{13}$ low quality of life predicted recurrence of depression in patients with bipolar or recurrent depressive disorders. ${ }^{14}$

The three kinds of interventions of promotion, prevention, and treatment are interrelated and complementary; however, they are somewhat different from one another. ${ }^{2}$ In this regards, psychiatrists also need to be competent in prevention of mental illnesses and mental health promotion in various settings. 
This review introduces the concepts, subjects, and intervention strategies for mental health promotion and prevention of mental illnesses to facilitate more engagement with these subjects.

\section{THE CONCEPTS}

Health promotion mainly deals with the determinants of mental health and aims to keep people healthy or become even healthier. ${ }^{2,4}$ In other words, mental health promotion aims at enhancing individual's ability to achieve psychosocial well-being and at coping with adversity. ${ }^{4}$

On the other hand, prevention of illnesses focuses on the causes of risk factors to avoid illness. ${ }^{2}$ There are three categories of prevention: primary prevention focuses on various determinants in the whole population or in the high risk group. Secondary prevention comprises early detection and intervention. Tertiary prevention targets for advanced recovery and reduction of relapse risk.

As you see, the concepts of promotion and prevention are interrelated and overlapped. Indeed, the direct causal pathway is not generally established in most mental illnesses, but rather multiple factors including both risk and protective factors contribute to the development of them. Therefore, mental health promotion might involve specific activities for prevention and some researchers used mental health promotion as a general term including both concepts. ${ }^{15}$ Mental health promotion and illness prevention were also taken together in the present review.

\section{TARGET POPULATIONS AND TOPICS}

In regards of mental health promotion, the whole population is the possible target of mental health promotion. Across the individual's lifespan, facilitating the development and timed achievement of goals are essential in mental health. Evaluating the achievement of relevant developmental task could be a meaningful topic in mental health promotion and illness prevention. In addition, age and gender of target population are related to prevalent major mental health problems, risk factors, and effective intervention strategies. Considering these, we scoped the subjects of mental health promotion and illness prevention according to the age group and then, mentioned issues on gender difference.

\section{Children and adolescents}

The period of child and adolescence is the time when mental illness is often developed and firstly diagnosed. Indeed, half of the lifetime mental illness is started by age $14 .{ }^{16}$ The mental health of school children and adolescents exerts neg- ative impacts on their school performance, peer rejection, risky behaviors, and future health. ${ }^{17,18}$ Among those aged 1024 years, mental illness is one of the main causes of years lost due to disability, contributing to about $45 \%$ of disability-adjusted life-years. ${ }^{19}$

Children and adolescents undergo brain development, and the prefrontal cortex, in particular, continues to develop until early adulthood. ${ }^{20}$ Therefore, the brain in childhood and adolescence is vulnerable for social, emotional, and behavioral adversities. Family disruption and low socioeconomic status as well as childhood maltreatment or other adversity might be risk factors for mental illnesses. ${ }^{21}$ In particular, various types of childhood maltreatment, such as emotional, physical, and sexual abuse, were associated with many forms of mental illnesses including both internalizing and externalizing psychopathology. ${ }^{22}$ Despite its clinical significance, childhood maltreatment is often missing in routine evaluation. ${ }^{23}$ On the other hand research on resilience in high-risk children facing various adversity have shown that self-efficacy, self-esteem, higher cognitive abilities, planning skills, family cohesion, social skills with close and supportive relationships with an adults were associated with adaptive coping and lower psychopathology.

Childhood and adolescence is considered a challenging period for developing the foundation for mental health and healthy behaviors (e.g., tobacco, alcohol, and eating habits) that prevent both mental and physical health problems. ${ }^{24}$ Identifying both risk factors and protective factors with targeted intervention and screening of psychiatric symptoms are important issues of mental health promotion and prevention of mental illnesses in this age group.

In addition to the role of family, that of school for mental health as an important social environment is crucial for children and adolescents. ${ }^{18}$ Accordingly, various school-based mental health interventions have been studied. ${ }^{24}$ Intervention programs targeted to mental health promotion and well-being have shared methods such as cognitive behavioral therapy (CBT), social skills training for children or adolescence, parent training, and teacher training. ${ }^{25}$ The goals of these interventions are the acquisition of social and emotional skills, competencies, and strong relationship between students and teachers that might be protective for various internalizing and externalizing problems while facilitating positive development and emotional well-being. ${ }^{24,26-28}$ Although the effect of intervention seems to be greater in high risk groups, a possible ceiling effect and small to modest effect in the whole children and adolescents need to be considered. ${ }^{24}$ Moreover, a recent review suggested that preventive intervention for adolescents needs focus on the common determinants of health as a whole in conjunction with education rather than on specific 
diseases or problems. ${ }^{18}$ For better and lasting interventions for mental health promotion of children and adolescence, cognitive-behavioral therapy approaches, early start with continuing booster sessions, a whole-school approach using leaders in the school, such as teachers and peers, liaisons with parents and community, and availability of outside agencies, such as psychiatrist are recommended. ${ }^{24}$

With the advent of IT technology, problematic overuse of internet or online game, social network services and text messaging have been emerged as an important issue among children and adolescents. ${ }^{29,30}$ Since they have limited self-regulation capacity and high dependence on peer pressure, children and adolescents may be vulnerable to overuse problems with internet, online games, and social media. ${ }^{29}$ Although there is some controversy, internet game addiction and excessive mobile telephone use were reported to be associated with potential negative impacts on cognitive function in this population. ${ }^{31,32}$ Educational and preventive programs for healthy use of social media involving parents, school, psychiatrist, and counselors might be an additional urgent issue for mental health for children and adolescents.

\section{Adults}

Since adults comprise a large proportion of the working population as well as providing support children and older adults, mental health in this population has the utmost importance for society. ${ }^{4}$ Mental disorders in adults contribute to lost work productivity, ${ }^{33}$ and predict mental disorders in their offspring. ${ }^{34}$

Work-related stress or job stress is one of the major mental health problems during adulthood. ${ }^{35}$ It is associated with negative lifestyle behavior, such as smoking, drinking and obesity, ${ }^{36,37}$ and poor mental health, such as insomnia ${ }^{38,39}$ and depression. ${ }^{40}$ Job stress is defined as "harmful physical and emotional responses that occur when the requirements of a job do not match the capabilities, resources, or needs of the workers." 41 Stressors in job stress are often the characteristics of job itself and problems in social or organizational context. However, a psychosocial approach along with the primary prevention strategies might also be crucial because development of individual coping skills and social support from supervisors and co-workers could contribute to mitigation of job stress, ${ }^{35}$ For example, a communication competence as well as associated social support and integrating conflict style were predictive of decreased job stress and increased job satisfaction. ${ }^{42}$ Management of job stress usually involves identification, assessment, and referral to medical resources outside the company, such as clinics, hospitals, and employee assistance programs (EAPs). ${ }^{35}$ Cognitive-behavioral interventions may be more effective than other types, such as psychodynamic, ed- ucational, and multimodal approaches. ${ }^{43,44}$

Satisfactory marital relationship and parenting are important developmental tasks during adulthood. Relationship quality and parenting stress are closely related. ${ }^{45}$ Good parentchild relationships contribute to better mental health for both children and parents. ${ }^{46}$ During the first year of a child's life, higher maternal stress was associated with parental dissatisfaction, poor child sleeping patterns, lack of social support and confidence/security. ${ }^{47}$ This increased parent's stress might lead to more punitive parenting attitudes whereas increased mutual support between partners might lead to favorable attitude in parenting. ${ }^{48}$ Therefore, early interventions are needed for promoting parental mental and physical health as well as supporting good parenting skills. Various parent-training programs have been developed and their efficacy shown in a meta-analysis. ${ }^{46}$ In this meta-analysis, cognitive-behavioral and rational emotive therapy programs were more effective in relieving guilt and improving parental moods, whereas the behavioral and multi-modal programs improved parenting competence and social support. The cognitive component focuses on cognitive distortions and techniques for dealing with such distortions while the behavioral component teaches child management skills, such as using clear, calm instructions, logical consequences for misbehavior, planned ignoring, and timeout. ${ }^{46}$ Some researchers suggested a multilevel parenting program according to the severity of children's behavior, emotional, and developmental problems. ${ }^{49}$ At any level of children's problems, enhancement of the knowledge, skills, and confidence of parents might be helpful in reducing parent stress.

\section{Old age}

The number of individuals over the age of 60 is rapidly growing worldwide. ${ }^{50}$ Older adults encounter retirement, bereavement, and fear of their own death as well as being more biologically vulnerable to depression. ${ }^{51}$ However, researchers reported generally lower frequency of depression in older adults than younger adults. ${ }^{52}$ The socio-emotional selectivity, in that older adults tend to de-emphasize negative experience and prioritize emotionally meaningful goals, and increased wisdom are thought to contribute to protection from risk factors. ${ }^{51}$ In fact, individual psychological resources, such as selfesteem and mastery as well as social network and social support are regarded as essential for better mental health in older people. ${ }^{4,53}$ A moderate level of physical activity or exercise is also related to reduced depression and anxiety as well as improved quality of life in seniors. ${ }^{54}$ In a systematic review of psychosocial interventions for promoting mental health and preventing depression in older adults, physical exercise, skill training, reminiscence, social activities, group support and multi-component interventions showed positive effects on 
quality of life and mental health as well as reduction in depressive symptoms in a pooled analysis. ${ }^{53}$ This review suggested that social activities significantly improved positive mental health, life satisfaction, and quality of life and reduced depressive symptoms. Skill training comprising interventions with education components, development of coping skills or management strategies also had a significant effect on positive mental health. Interventions lasting more than 3 months showed more positive effect than shorter interventions overall. ${ }^{53}$

Successful cognitive aging is a central topic to older adults. Preventing the loss of information processing capacity and cognitive reserve as well as enhancing brain capacity and cognitive reserve are the dual goals of the successful cognitive aging. ${ }^{55}$ For the first goal, clinical conditions that reduce cognitive reserve and intellectual capacity, such as vascular risk factors, sleep disorders, metabolic dysfunction, mood disorders, and medication side effects, need to be identified and treated. Meanwhile, it has been demonstrated that physical activity and cognitively stimulating activity enhance cognitive performance and reduce the likelihood of developing dementia. The level of total daily physical activity was associated with a slower rate of global cognitive decline and a reduced risk of Alzheimer's disease (AD) after controlling for other risk factors. ${ }^{56,57}$ Greater engagement of mental, social, and productive activity may protect against dementia. ${ }^{55}$ In particular, the quality and extent of an individual's social network are protective in cognitive aging. ${ }^{58}$ Based on these, exercise intervention and cognitive training programs have been used to challenge older adults. Interventions for increasing physical activity improved cognition in relatively healthy older adults, ${ }^{59,60}$ and in patients with early dementia. ${ }^{61}$ Of note, a six-month aerobic fitness training demonstrated increased brain volumes and functional plasticity among in patients with early dementia and otherwise healthy subjects. ${ }^{59,60,62}$ Even in patients with dementia, exercise was beneficial in reducing some symptoms of behavioral and psychological symptoms of dementia, such as depression, agitation, and wandering. ${ }^{63}$ Cognitive training for memory, reasoning, and speed of processing reported lasting improvements in targeted functioning, especially with booster training. ${ }^{64,65}$ Although antioxidants, Ginkgo biblova, and nutritional factors showed positive effects on promoting successful cognitive aging, more evidence is needed to confirm their effects. ${ }^{55}$

\section{Gender difference}

The prevalence and clinical manifestations of mental illnesses differ significantly by sex. For instance, the risk of depression and some anxiety disorders, such as panic disorder, social anxiety disorder, and generalized anxiety disorder, is higher in women than in men. ${ }^{66}$ Since mothers' mental health affects the mental health of their children and families, ${ }^{66}$ promoting women's mental health might contribute to better family's mental health.

Women experience greater hormonal changes across the lifespan than men and face different psychosocial stressors. ${ }^{4}$ Brain morphology as well as structural and functional connectivity are different by gender. ${ }^{67}$ Reproductive-related events, such as menstrual cycle, use of hormonal contraception, pregnancy, postpartum, and menopause, also potentially influence women's mental health. ${ }^{68,69}$ Additionally, women are more likely to experience rape and domestic abuse. Women are more sensitive to social network crises that are stressors in relationships with acquaintances, friends, or loved ones. ${ }^{70}$ Gender role socialization and the tendency of higher anxiety and rumination as well as lower self efficacy in women also contribute to the increased vulnerability to anxiety in the face of adversity. ${ }^{70}$ Reproductive phase, stressors, and cognitive and emotional coping styles need to be considered in approaches of mental health promotion and illness prevention.

\section{INTERVENTIONS}

Interventions might be categorized into universal (the whole population), selected (the subgroups with significant risks), and indicated (high-risk individuals) according to the range of target population. ${ }^{71}$ However, various interventions for mental health promotion and illness prevention might be overlapped. In this section, intervention strategies or components that are commonly involved in interventions mental health promotion or illness preventions were introduced as follows: 1 ) lifestyle medicine, 2) stress management skills training, and 3) preventive consultation and positive psychotherapy.

\section{Lifestyle medicine}

Stress and mental health problems are closely related to unhealthy lifestyles that are risk factors for mental and physical health. ${ }^{72,73}$ Therefore, healthy behavior intervention contributes to mental and physical health as well as to the management of stress itself. ${ }^{74,75}$ Along with the increase in lifestyle diseases, therapeutic lifestyle change has become an important target for interventions for both physical ${ }^{73,75,76}$ and mental health promotion. ${ }^{11,77}$ Therapeutic lifestyle change (TLC) focused on smoking, alcohol use, diet, physical activity or exercise, obesity, and stress management. Healthy lifestyle is encouraged in the general population and is more strongly recommended in high risk populations to prevent or ameliorate mental and physical health problems.

Regarding substance use, cigarette smoking is the most important preventable risk factor for various illnesses. ${ }^{78}$ After the assessment of the severity of dependence and a patient's will- 
ingness to quit, behavioral intervention with education, motivational interviewing and pharmacotherapy with bupropion or varenicline are helpful evidence-based approaches. ${ }^{79}$ In addition, consultation and education for low-risk drinking could to be provided in lifestyle medicine. Although there is no consensus guideline, low-risk drinking guidelines generally involve the following: 1) Intake less than 1-2 and 2-3 standard drinks per day for healthy female and males, respectively. 2) Intake less than 7 and 14 standard drinks per week for healthy male and females, respectively. ${ }^{80,81} 3$ ) Do not drink alcohol when operating any kind of vehicle or machinery, using medications interacting with alcohol, engaging in potentially dangerous physical activities, pregnant or planning to be, breastfeeding, suffering from serious physical or mental illness, or for children and adolescents. As in the interventions for smoking cessation, behavioral intervention with education and motivational interviewing might be helpful in guiding lowrisk drinking.

Physical activity is also challenging issue for mental health promotion and prevention. As already mentioned, effects of physical activity and exercise have been reported for depression, anxiety, cognition and other mental health problems, with the best evidence for depression. ${ }^{82-85}$ Therefore, exercise is strongly recommended as an integral part of mental health promotion, preventions, and management across all ages. ${ }^{82}$ Regarding the mediating mechanisms, modulation of neurotransmitter system, such as noradrenergic and serotonergic system, ${ }^{86}$ and increased both BDNF dependent- and independent-hippocampal plasticity have been reported. ${ }^{87,88}$ Moderate exercise is hypothesized to counteract the influences of chronic stress in various brain regions. ${ }^{89} \mathrm{~A}$ qualitative review also indicated psychosocial mechanisms of the effect of exercise including increased opportunity for social interaction, greater confidence, sense of meaning and achievement, and feeling of safety. ${ }^{82}$ Furthermore, exercise might lead to reduced anxiety sensitivity or trait anxiety and vulnerability to psychosocial stress ${ }^{83,90}$ as well as increased well-being. ${ }^{85}$ Aerobic exercise or walking of 2030 min duration between three to five times per week is recommended generally. ${ }^{83} \mathrm{~A}$ pedometer and a self-rated exercise log can be used to monitor physical activity each day. ${ }^{73}$ More specifically, the prescription of exercise type, frequency, intensity, or duration would be tailored in considerations of contextual factors, such as medical conditions, body size, medications, support system, psychosocial issues. ${ }^{91}$

Healthy eating should be encouraged in TLC. Assessment of dietary habits, education, setting a dietary goal, and assessing dietary intake constitutes the lifestyle intervention for healthy eating. ${ }^{73} \mathrm{~A}$ more plant-food-based diet including whole grain, legumes, vegetables, and fresh fruits is recommended. Fat, animal protein, sugar, salt are recommended to be reduced in intake. Obesity is a lifestyle-related disease along with type-2 diabetes mellitus and cardiovascular disease. Obesity is also associated with higher risk of mental illness and reduced psychological well-being, especially in women.${ }^{92}$ Weight cycling as well as obesity were associated with depression, alcoholism, other drug dependence, low self-esteem, and poor health perception. ${ }^{93}$ Physical activity or exercise, dietary control, behavior therapy, and continuous patient-therapist contact are the principal components of lifestyle modification for weight control..$^{94}$ In this respect, lifestyle modification intervention is usually provided by a team comprising dietitians, psychologists or psychiatrist, and exercise specialists.

However, changing lifestyle is often difficult despite broad recommendations. In fact, multiple risk factors intervention using counseling and education aimed at behavioral changes reported limited efficacy in reducing mortality of coronary heart disease. ${ }^{95,96}$ For successful lifestyle modification, individual motivation to care for his or her own health is critical. ${ }^{97}$ In this context, cognitive-behavioral intervention program using the motivational interviewing and problem solving might be effective in producing behavioral changes. ${ }^{98}$ As a principal component of changing lifestyle, motivational interviewing is the patient-centered collaborative approach for enhancing internal motivation for change by exploring and resolving the ambivalence toward a target problem. ${ }^{75}$ Expression of empathy, supporting self-efficacy of the client, rolling with resistance through encouraging the client to develop his own solutions, and development of discrepancy between their situation and expectations are the four general principles of motivational interviewing. ${ }^{99}$ Meta-analyses demonstrated that motivational interviewing is effective in improving body mass index, cardiovascular risk factors, smoking, alcohol use, exercise, and psychological problems. ${ }^{100-102}$ In addition to face-to-face interview with the client, the motivational enhancement approaches using tailored print communication and telephone interviewing were also effective in increasing physical activity, consumption of fruit and vegetables in middle-aged adults. ${ }^{103}$ This effect is regardless of the presence of hypertension. For children and adolescence, a team-based approach using motivational interviewing with parents and children might be valid in managing diet, physical activity, and behaviors in overweight children. ${ }^{104}$ Continuous support with encouraging motivation would be helped by joining the alumni association of TLC. ${ }^{73}$

\section{Stress management skills training}

Managing daily life stress and helping recovery from adversity are important for mental health promotion. ${ }^{4}$ Since the interaction of the brain, mind, and body is involved in stress reaction, interventions based on mind-body medicine have 
been suggested as an effective mean for managing stress. ${ }^{105}$ Along with the TLC that is the basis of stress management, ${ }^{11}$ more focused approaches have been developed as follows.

Cognitive behavioral approaches, so called cognitive-behavioral stress management (CBSM), are the most widely researched interventions based on the notion that cognition influences emotions and behavior. ${ }^{106}$ Therefore, the primary goal of the therapy is the finding irrational thought patterns and replacing those with more rational thoughts. It also includes behavioral techniques, such as breathing and relaxation exercises. CBSM is usually performed as a group-based 10week program. Topics included cognitive-behavioral theory of stress, emotions, thoughts, and physiological responses, identification of replacement of irrational automatic thoughts, coping skills training, assertiveness training, anger management, and increasing the use of social support. Relaxation exercises such as, progressive muscle relaxation and abdominal breathing are also included. CBSM comprised of in-session exercise and homework to apply these techniques to personal life experiences. Researchers have been demonstrated that CBSM is associated with improvement of health-related outcomes and reduced perceived stress and stress-related physiological responses in patients with cancer, ${ }^{107,108}$ human immunodeficiency virus infection, ${ }^{109}$ and chronic fatigue syndrome, ${ }^{110}$ as well as healthy subjects. ${ }^{111,112}$

Recently, meditation-based approaches, such as mindfulness-based stress reduction (MBSR), have come into wide use. ${ }^{113,114}$ These stress management program are shown to be effective in both nonclinical healthy subjects and patients with mental and physical illnesses. ${ }^{106,113}$ MBSR is a group program that focuses upon the progressive acquisition of mindfulness. The construct of MBSR was adapted from the Buddhist practice of meditation to enable people to better cope with illness, stress, and pain. ${ }^{115}$ It hypothesized that the development of the ability to sustain attention to moment-to-moment experiences by regular practice will provide a more accurate perception of one's own response to stimuli, greater sense of control, and vital sense of life. ${ }^{113}$ MBSR is a structured 8-10 week group program with homework that includes different forms of mindfulness meditation practice, such as meditation, yoga, and body scanning. ${ }^{116}$ For example, "sitting meditation" involves awareness of body sensation, thoughts, and emotions while continually returning the focus of attention to the breath. "Body scan" refers to a progressive movement of attention through the body from toes to head observing any sensations in body. Additionally, the loving kindness meditation, forgiveness, mindful listening skills might be added in need. ${ }^{117}$ Meta-analyses showed that MBSR might be a useful intervention for a broad range of chronic disorders ${ }^{113}$ and for stress reduction in healthy subjects. ${ }^{118}$ In healthy subjects, it also reduces rumination and trait anxiety as well as enhances empathy and spirituality. ${ }^{118}$

\section{Preventive consultation and positive psychotherapy}

Based on the theory of Maslow's 'Hierarchy of needs' ${ }^{\text {'19 }}$ and Antonovsky's 'salutogenic perspective' in health promotion, ${ }^{120}$ improved health-related quality of life and self-efficacy with positive lifestyle change were achieved by interventions dealing with resources and barriers to selected goals. ${ }^{121}$ This result is in line with the result in population-based cohort study whereby a high sense of coherence was independently associated with healthy lifestyle. ${ }^{122}$ Therefore, psychotherapeutic intervention for enhancing self efficacy and sense of coherence might be important. The effect of a structured 1-hour preventive consultation provided by general practitioners was shown in a recent study in Denmark. ${ }^{121}$ In this study, patient chose the consultation topics among social life, health, lifestyle, reaction on stressors. The patient chooses one or two goals for a better life and then, time schedules and specific barriers and resources for attaining the goals were discussed and described in the report. This preventive consultation significantly improved mental health and quality of life.

In line with these, the concepts of positive psychotherapy and resilience enhancement have been introduced in interventions for mental health promotion and prevention. Strengthening protective factors as well as the removal or reducing risk factors are the important strategies to promote mental health and illness prevention. ${ }^{71}$ Positive psychotherapy aims to increase positive emotion, engagement, and meaning rather than to target psychological problems. ${ }^{123}$ Among various interventions to improve quality of life, well-being or happiness, quality of life therapy was developed as an approach to improving quality of life. ${ }^{124}$ In this therapy, client assesses current levels of quality of life across multiple life domains, such as health, self-esteem, goals and values, standard of living, work, recreation, learning, creativity, helping or social service and civic action, love relationship, friendships, relationships with children, relationships with relatives, home, neighborhood, and community. Client and therapist attempt to change the circumstances, attitudes, standard of fulfillment, and relative importance of selected two to five domains. Among adults awaiting lung transplantation, individuals receiving telephone-based quality of life therapy demonstrated significantly higher quality of life at 1- and 3-month follow-up assessments. ${ }^{125}$ Meanwhile, well-being therapy ${ }^{126}$ is based on Ryff's model of psychological well-being. ${ }^{127}$ This model has six dimensions of environmental mastery, personal growth, purpose in life, autonomy, self -acceptance, and positive relations with others. Well-being therapy comprises 8-12 sessions in which initial sessions focus on self-observation with using 
a structure diary and subsequent sessions emphasize skill development and sustaining attentions to daily experience. In high risk population, decreased vulnerability to depression and anxiety was shown. ${ }^{126}$ In addition, gratitude visit (write and deliver a letter of gratitude), three good things in life (write down three things went well each day and their causes every night), you at your best (write about a time when individual were at their best and reflect on their strength), identifying signature strengths and using them in a new way are positive interventions with reported efficacy. ${ }^{128}$

The term resilience refers to the positive side of individual differences in people's responses to stress and adversity. ${ }^{129} \mathrm{Al}$ though the definition of resilience has not yet been established, various contributing personal and environmental factors that might seem to work together were found. ${ }^{130}$ Researchers have suggested that demographic variables, personal attributes, such as internal locus of control and active coping strategies, ${ }^{131}$ positive psychological factors, such as hope, optimism, gratitude and purpose in life, ${ }^{132}$ and socio-contextual factors, such as supportive relationships and community resources, ${ }^{129,133}$ contribute to resilience in both children and adults. Spirituality and religion have also been suggested to have a protective effect for mental health. ${ }^{134,135}$ Various interventions to enhance and strengthen resilience factors might contribute to mental health promotion and illness prevention. ${ }^{71}$ As an example of resilience enhancement intervention, READY program ${ }^{12}$ based on five resilience factors of positive emotions, cognitive flexibility, social support, life meaning, and active coping. ${ }^{136}$ This program consists of approaches of acceptance and commitment therapy including processes of acceptance, mindfulness, defusion, life values, social connectedness, relaxation, and pleasant activities, and activating and troubleshooting strategies as well as physical activity. Despite a pilot study, a significant improvement in psychosocial well-being was reported. ${ }^{12}$

\section{Community intervention}

Increase in public awareness of mental health might be needed to increase the acceptance of mental health care for promotion and prevention of illnesses. ${ }^{137}$ Education for earlier recognition of problems and appropriate help-seeking would be important issues. Moreover, social network and social support may prevent mental health problems, such as mental health problems in children and cognitive decline, as well as promote well-being. ${ }^{71}$ Community-based interventions including education and enhancing social capitals might contribute to mental health promotion.

\section{CONCLUSIONS}

The message that there is no health without mental health is worthy of notice. ${ }^{138}$ Indeed, mental health is closely related to physical health, interventions for promoting mental health, such as stress management, will also improve physical health. With the increased interest for mental health and its management, mental health promotion and prevention of illnesses have become principal challenges for psychiatrists in addition to the treatment of mental illnesses. Since comprehensive knowledge of bio-psycho-social factors contributing to mental health and various psychotherapeutic skills are essential for these issues, psychiatrists can do best. Understanding for developmental psychology and lifestyle medicine as well as macroscopic perspective that considers individual, family, school, and community might be helpful. Further research on clinical screening method of mental health and practical guidelines of intervention strategies for mental health promotion and illness prevention are required.

\section{REFERENCES}

1. WHO. The World Health Organization Quality of Life assessment (WHOQOL): position Paper from the World Health Organization. Soc Sci Med 1995;41:1403-1409.

2. Herrman H. The need for mental health promotion. Aust N Z J Psychiatry 2001;35:709-715.

3. Ryff CD, Singer B. Psychological well-being: meaning, measurement, and implications for psychotherapy research. Psychother Psychosom 1996;65:14-23.

4. Kalra G, Christodoulou G, Jenkins R, Tsipas V, Christodoulou N, LecicTosevski D, et al. Mental health promotion: Guidance and strategies. Eur Psychiatry 2012;27:81-86.

5. Monshat K, Herrman $\mathrm{H}$. What does 'mental health promotion' mean to psychiatry trainees? Australas Psychiatry 2010;18:589.

6. Olfson M, Broadhead WE, Weissman MM, Leon AC, Farber L, Hoven C, et al. Subthreshold psychiatric symptoms in a primary care group practice. Arch Gen Psychiatry 1996;53:880-886.

7. Karsten J, Hartman CA, Smit JH, Zitman FG, Beekman AT, Cuijpers P, et al. Psychiatric history and subthreshold symptoms as predictors of the occurrence of depressive or anxiety disorder within 2 years. Br J Psychiatry 2011;198:206-212.

8. WHO. Mental Health Action Plan for Europe: Facing the Challenges, Building Solutions. Helsinki, Finland: World Health Organization; 2005.

9. Wood AM, Joseph S. The absence of positive psychological (eudemonic) well-being as a risk factor for depression: a ten year cohort study. J Affect Disord 2010;122:213-217.

10. Power AK. Transforming the Nation's Health: next steps in mental health promotion. Am J Public Health 2010;100:2343-2346.

11. Kim B, Yoon DH. Psychiatry in health promotion: health psychiatry. J Korean Neuropsychiatr Assoc 2011;50:90-96.

12. Burton NW, Pakenham KI, Brown WJ. Feasibility and effectiveness of psychosocial resilience training: a pilot study of the READY program. Psychol Health Med 2010;15:266-277.

13. Min JA, Lee NB, Lee CU, Lee C, Chae JH. Low trait anxiety, high resilience, and their interaction as possible predictors for treatment response in patients with depression. J Affect Disord 2012;137:61-69.

14. Thunedborg K, Black CH, Bech P. Beyond the Hamilton depression scores in long-term treatment of manic-melancholic patients: prediction of recurrence of depression by quality of life measurements. Psychother Psychosom 1995;64:131-140.

15. Lehtinen V, Riikonene E, Lahtinene E. Promotion of Mental Health 
on the European Agenda. Helsinki: STAKES, National Research and Development Centre for Welfare and Health; 1997.

16. Kessler RC, Berglund P, Demler O, Jin R, Merikangas KR, Walters EE. Lifetime prevalence and age-of-onset distributions of DSM-IV disorders in the National Comorbidity Survey Replication. Arch Gen Psychiatry 2005;62:593-602.

17. DeSocio J, Hootman J. Children's mental health and school success. J Sch Nurs 2004;20:189-196.

18. Sawyer SM, Afifi RA, Bearinger LH, Blakemore SJ, Dick B, Ezeh AC, et al. Adolescence: a foundation for future health. Lancet 2012;379: 1630-1640.

19. Gore FM, Bloem PJ, Patton GC, Ferguson J, Joseph V, Coffey C, et al. Global burden of disease in young people aged 10-24 years: a systematic analysis. Lancet 2011;377:2093-2102.

20. Lenroot RK, Giedd JN. Brain development in children and adolescents: insights from anatomical magnetic resonance imaging. Neurosci Biobehav Rev 2006;30:718-729.

21. Rutter M. Pathways from childhood to adult life. J Child Psychol Psychiatry 1989;30:23-51.

22. Keyes KM, Eaton NR, Krueger RF, McLaughlin KA, Wall MM, Grant $\mathrm{BF}$, et al. Childhood maltreatment and the structure of common psychiatric disorders. Br J Psychiatry 2012;200:107-115.

23. Read J, Bentall RP. Negative childhood experiences and mental health: theoretical, clinical and primary prevention implications. Br J Psychiatry 2012;200:89-91.

24. Weare K, Nind M. Mental health promotion and problem prevention in schools: what does the evidence say? Health Promot Int 2011;26 (Suppl 1):i29-i69.

25. Catalano RF. Positive youth development in the United States: Research findings on evaluations of positive youth development programs. Ann Am Acad Pol Soc Sci 2004;591:98.

26. Kimber B, Sandell R, Bremberg S. Social and emotional training in Swedish schools for the promotion of mental health: an effectiveness study of 5 years of intervention. Health Educ Res 2008;23:931-940.

27. Merry S, McDowell H, Hetrick S, Bir J, Muller N. Psychological and/or educational interventions for the prevention of depression in children and adolescents. Cochrane Database Syst Rev 2004;(1):CD003380.

28. Mytton J, DiGuiseppi C, Gough D, Taylor R, Logan S. School-based secondary prevention programmes for preventing violence. Cochrane Database Syst Rev 2006;(3):CD004606.

29. McBride DL. Risks and benefits of social media for children and adolescents. J Pediatr Nurs 2011;26:498-499.

30. Gentile DA, Choo H, Liau A, Sim T, Li D, Fung D, et al. Pathological video game use among youths: a two-year longitudinal study. Pediatrics 2011;127:e319-e329.

31. Abramson MJ, Benke GP, Dimitriadis C, Inyang IO, Sim MR, Wolfe $\mathrm{RS}$, et al. Mobile telephone use is associated with changes in cognitive function in young adolescents. Bioelectromagnetics 2009;30:678-686.

32. Park MH, Park EJ, Choi J, Chai S, Lee JH, Lee C, et al. Preliminary study of Internet addiction and cognitive function in adolescents based on IQ tests. Psychiatry Res 2011;190:275-281.

33. Chong SA, Vaingankar JA, Abdin E, Subramaniam M. Mental disorders: employment and work productivity in Singapore. Soc Psychiatry Psychiatr Epidemiol 2013;48:117-123.

34. McLaughlin KA, Gadermann AM, Hwang I, Sampson NA, Al-Hamzawi A, Andrade LH, et al. Parent psychopathology and offspring mental disorders: results from the WHO World Mental Health Surveys. Br J Psychiatry 2012;200:290-299.

35. Nakao M. Work-related stress and psychosomatic medicine. Biopsychosoc Med 2010;4:4

36. Takaki J, Minoura A, Irimajiri H, Hayama A, Hibino Y, Kanbara S, et al. Interactive effects of job stress and body mass index on over-eating. J Occup Health 2010;52:66-73.

37. Noblet A, Lamontagne AD. The role of workplace health promotion in addressing job stress. Health Promot Int 2006;21:346-353.
38. Kim HC, Kim BK, Min KB, Min JY, Hwang SH, Park SG. Association between job stress and insomnia in Korean workers. J Occup Health 2011;53:164-174

39. Nishitani N, Sakakibara H. Job stress factors, stress response, and social support in association with insomnia of Japanese male workers. Ind Health 2010;48:178-184.

40. Stoetzer U, Ahlberg G, Johansson G, Bergman P, Hallsten L, Forsell Y, et al. Problematic interpersonal relationships at work and depression: a Swedish prospective cohort study. J Occup Health 2009;51:144-151.

41. NIOSH. National Institute for Occupational Safety and Health: Stress at Work. Cincinnati: NIOSH; 1999.

42. Wright KB. A communication competence approach to healthcare worker conflict, job stress, job burnout, and job satisfaction. J Healthc Qual 2011;33:7-14.

43. Isaksson Ro KE, Tyssen R, Hoffart A, Sexton H, Aasland OG, Gude T. A three-year cohort study of the relationships between coping, job stress and burnout after a counselling intervention for help-seeking physicians. BMC Public Health 2010;10:213.

44. van der Klink JJ, Blonk RW, Schene AH, van Dijk FJ. The benefits of interventions for work-related stress. Am J Public Health 2001;91:270-276.

45. Pedro MF, Ribeiro T, Shelton KH. Marital satisfaction and partners' parenting practices: the mediating role of coparenting behavior. J Fam Psychol 2012;26:509-522.

46. Barlow J, Coren E. Parent-training programmes for improving maternal psychosocial health. Cochrane Database Syst Rev 2004;(1):CD002020.

47. Sepa A, Frodi A, Ludvigsson J. Psychosocial correlates of parenting stress, lack of support and lack of confidence/security. Scand J Psychol 2004;45:169-179.

48. McCurdy K. The influence of support and stress on maternal attitudes. Child Abuse Negl 2005;29:251-268.

49. de Graaf I, Speetjens P, Smit F, de Wolff M, Tavecchio L. Effectiveness of the Triple P Positive Parenting Program on behavioral problems in children: a meta-analysis. Behav Modif 2008;32:714-735.

50. Department of Economic and Social Affairs PD. World Population Ageing. New York: United Nations Publications; 2007.

51. Blazer DG 2nd, Hybels CF. Origins of depression in later life. Psychol Med 2005;35:1241-1252.

52. Luijendijk HJ, van den Berg JF, Dekker MJ, van Tuijl HR, Otte W, Smit F, et al. Incidence and recurrence of late-life depression. Arch Gen Psychiatry 2008;65:1394-1401.

53. Forsman AK, Nordmyr J, Wahlbeck K. Psychosocial interventions for the promotion of mental health and the prevention of depression among older adults. Health Promot Int 2011;26(Suppl 1):i85-i107.

54. Antunes HK, Stella SG, Santos RF, Bueno OF, de Mello MT. Depression, anxiety and quality of life scores in seniors after an endurance exercise program. Rev Bras Psiquiatr 2005;27:266-271.

55. Daffner KR. Promoting successful cognitive aging: a comprehensive review. J Alzheimers Dis 2010;19:1101-1122.

56. Buchman AS, Boyle PA, Yu L, Shah RC, Wilson RS, Bennett DA. Total daily physical activity and the risk of $\mathrm{AD}$ and cognitive decline in older adults. Neurology 2012;78:1323-1329.

57. Wang L, Larson EB, Bowen JD, van Belle G. Performance-based physical function and future dementia in older people. Arch Intern Med 2006;166:1115-1120.

58. Fratiglioni L, Wang HX, Ericsson K, Maytan M, Winblad B. Influence of social network on occurrence of dementia: a community-based longitudinal study. Lancet 2000;355:1315-1319.

59. Colcombe SJ, Erickson KI, Scalf PE, Kim JS, Prakash R, McAuley E, et al. Aerobic exercise training increases brain volume in aging humans. J Gerontol A Biol Sci Med Sci 2006;61:1166-1170.

60. Colcombe SJ, Kramer AF, Erickson KI, Scalf P, McAuley E, Cohen NJ, et al. Cardiovascular fitness, cortical plasticity, and aging. Proc Natl Acad Sci U S A 2004;101:3316-3321.

61. Yerokhin V, Anderson-Hanley C, Hogan MJ, Dunnam M, Huber D, Osborne S, et al. Neuropsychological and neurophysiological effects 
of strengthening exercise for early dementia: a pilot study. Neuropsychol Dev Cogn B Aging Neuropsychol Cogn 2012;19:380-401.

62. Erickson KI, Voss MW, Prakash RS, Basak C, Szabo A, Chaddock L, et al. Exercise training increases size of hippocampus and improves memory. Proc Natl Acad Sci U S A 2011;108:3017-3022.

63. Thune-Boyle IC, Iliffe S, Cerga-Pashoja A, Lowery D, Warner J. The effect of exercise on behavioral and psychological symptoms of dementia: towards a research agenda. Int Psychogeriatr 2012;24:1046-1057.

64. Ball K, Berch DB, Helmers KF, Jobe JB, Leveck MD, Marsiske M, et al. Effects of cognitive training interventions with older adults: a randomized controlled trial. JAMA 2002;288:2271-2281.

65. Willis SL, Tennstedt SL, Marsiske M, Ball K, Elias J, Koepke KM, et al. Long-term effects of cognitive training on everyday functional outcomes in older adults. JAMA 2006;296:2805-2814.

66. Hales RE, Yudofsky SC, Gabbard GO. The American Psychiatric Publishing Textbook of Psychiatry. Washington DC: American Psychiatric Publishing, Inc.; 2008.

67. Gong G, He Y, Evans AC. Brain connectivity: gender makes a difference. Neuroscientist 2011;17:575-591.

68. Freeman EW, Sammel MD, Lin H, Nelson DB. Associations of hormones and menopausal status with depressed mood in women with no history of depression. Arch Gen Psychiatry 2006;63:375-382.

69. Oinonen KA, Mazmanian D. To what extent do oral contraceptives influence mood and affect? J Affect Disord 2002;70:229-240.

70. McLean CP, Anderson ER. Brave men and timid women? A review of the gender differences in fear and anxiety. Clin Psychol Rev 2009;29: 496-505.

71. Campion J, Bhui K, Bhugra D; European Psychiatric Association. European Psychiatric Association (EPA) guidance on prevention of mental disorders. Eur Psychiatry 2012;27:68-80.

72. Molarius A, Berglund K, Eriksson C, Eriksson HG, Linden-Bostrom M, Nordstrom E, et al. Mental health symptoms in relation to socio-economic conditions and lifestyle factors--a population-based study in Sweden. BMC Public Health 2009;9:302.

73. Aldana SG, Greenlaw RL, Diehl HA, Salberg A, Merrill RM, Ohmine S, et al. The behavioral and clinical effects of therapeutic lifestyle change on middle-aged adults. Prev Chronic Dis 2006;3:A05.

74. Happell B, Davies C, Scott D. Health behaviour interventions to improve physical health in individuals diagnosed with a mental illness: A systematic review. Int J Ment Health Nurs 2012;21:236-247.

75. Thomas SP. Editorial: Therapeutic Lifestyle Changes (TLCs) and Mental Health. Issues Ment Health Nurs 2012;33:199.

76. Brown TM, Sanderson BK, Bittner V. Drugs are not enough: the metabolic syndrome--a call for intensive therapeutic lifestyle change. J Cardiometab Syndr 2009;4:20-25.

77. Walsh R. Lifestyle and mental health. Am Psychol 2011;66:579-592.

78. WHO. WHO Report on the Global Tobacco Epidemic, 2008: The MPOWER Package. Geneva, Switzerland: World Health Organization; 2008.

79. Laniado-Laborin R. Smoking cessation intervention: an evidence-based approach. Postgrad Med 2010;122:74-82.

80. Dawson DA. US low-risk drinking guidelines: an examination of four alternatives. Alcohol Clin Exp Res 2000;24:1820-1829.

81. Stockwell T, Butt P, Beirness D, Gliksman L, Paradis C. The basis for Canada's new low-risk drinking guidelines: a relative risk approach to estimating hazardous levels and patterns of alcohol use. Drug Alcohol Rev 2012;31:126-134.

82. Mason OJ, Holt R. Mental health and physical activity interventions: a review of the qualitative literature. J Ment Health 2012;21:274-284.

83. Callaghan P. Exercise: a neglected intervention in mental health care? J Psychiatr Ment Health Nurs 2004;11:476-483.

84. Biddle SJ, Asare M. Physical activity and mental health in children and adolescents: a review of reviews. Br J Sports Med 2011;45:886-895.

85. Penedo FJ, Dahn JR. Exercise and well-being: a review of mental and physical health benefits associated with physical activity. Curr Opin
Psychiatry 2005;18:189-193.

86. Dishman RK. Brain monoamines, exercise, and behavioral stress: animal models. Med Sci Sports Exerc 1997;29:63-74.

87. Ferreira AF, Real CC, Rodrigues AC, Alves AS, Britto LR. Short-term, moderate exercise is capable of inducing structural, BDNF-independent hippocampal plasticity. Brain Res 2011;1425:111-122.

88. Griffin EW, Mullally S, Foley C, Warmington SA, O’Mara SM, Kelly AM. Aerobic exercise improves hippocampal function and increases BDNF in the serum of young adult males. Physiol Behav 2011;104:934941.

89. Sarbadhikari SN, Saha AK. Moderate exercise and chronic stress produce counteractive effects on different areas of the brain by acting through various neurotransmitter receptor subtypes: a hypothesis. Theor Biol Med Model 2006;3:33.

90. Smits JA, Tart CD, Rosenfield D, Zvolensky MJ. The interplay between physical activity and anxiety sensitivity in fearful responding to carbon dioxide challenge. Psychosom Med 2011;73:498-503.

91. Brody LT. Effective therapeutic exercise prescription: the right exercise at the right dose. J Hand Ther 2012;25:220-232.

92. Park E. Gender as a moderator in the association of body weight to smoking and mental health. Am J Public Health 2009;99:146-151.

93. Wyshak G. Weight change, obesity, mental health, and health perception: self-reports of college-educated women. Prim Care Companion J Clin Psychiatry 2007;9:48-54.

94. Wadden TA, Butryn ML, Byrne KJ. Efficacy of lifestyle modification for long-term weight control. Obes Res 2004;12(Suppl):151S-162S

95. Ebrahim S, Beswick A, Burke M, Davey Smith G. Multiple risk factor interventions for primary prevention of coronary heart disease. Cochrane Database Syst Rev 2006;(4):CD001561.

96. Ebrahim S, Taylor F, Ward K, Beswick A, Burke M, Davey Smith G. Multiple risk factor interventions for primary prevention of coronary heart disease. Cochrane Database Syst Rev 2011;(1):CD001561.

97. Waldhausl W. Motivation needed to cure lifestyle diseases. Nature 2007;450:945.

98. Lakerveld J, Bot SD, Chinapaw MJ, van Tulder MW, van Oppen P, Dekker JM, et al. Primary prevention of diabetes mellitus type 2 and cardiovascular diseases using a cognitive behavior program aimed at lifestyle changes in people at risk: Design of a randomized controlled trial. BMC Endocr Disord 2008;8:6.

99. Markland D. Motivational interviewing and self-determination theory. J Soc Clin Psychol 2005;24:811.

100. Armstrong MJ, Mottershead TA, Ronksley PE, Sigal RJ, Campbell TS, Hemmelgarn BR. Motivational interviewing to improve weight loss in overweight and/or obese patients: a systematic review and metaanalysis of randomized controlled trials. Obes Rev 2011;12:709-723.

101. Heckman CJ, Egleston BL, Hofmann MT. Efficacy of motivational interviewing for smoking cessation: a systematic review and meta-analysis. Tob Control 2010;19:410-416.

102. Rubak S, Sandbaek A, Lauritzen T, Christensen B. Motivational interviewing: a systematic review and meta-analysis. Br J Gen Pract 2005; 55:305-312.

103. van Keulen HM, Mesters I, Ausems M, van Breukelen G, Campbell M, Resnicow K, et al. Tailored print communication and telephone motivational interviewing are equally successful in improving multiple lifestyle behaviors in a randomized controlled trial. Ann Behav Med 2011; 41:104-118.

104. Taylor RW, Brown D, Dawson AM, Haszard J, Cox A, Rose EA, et al. Motivational interviewing for screening and feedback and encouraging lifestyle changes to reduce relative weight in 4-8 year old children: design of the MInT study. BMC Public Health 2010;10:271.

105. Le Tourneau M. Mind-body medicine for stress management and opportunities at NCCAM. Altern Ther Health Med 2003;9:18.

106. Smith BW, Shelley BM, Dalen J, Wiggins K, Tooley E, Bernard J. A pilot study comparing the effects of mindfulness-based and cognitive-behavioral stress reduction. J Altern Complement Med 2008;14:251-258. 
107. McGregor BA, Antoni MH, Boyers A, Alferi SM, Blomberg BB, Carver CS. Cognitive-behavioral stress management increases benefit finding and immune function among women with early-stage breast cancer. J Psychosom Res 2004;56:1-8.

108. Penedo FJ, Dahn JR, Molton I, Gonzalez JS, Kinsinger D, Roos BA, et al. Cognitive-behavioral stress management improves stress-management skills and quality of life in men recovering from treatment of prostate carcinoma. Cancer 2004;100:192-200.

109. Brown JL, Vanable PA. Cognitive-behavioral stress management interventions for persons living with HIV: a review and critique of the literature. Ann Behav Med 2008;35:26-40.

110. Lopez C, Antoni M, Penedo F, Weiss D, Cruess S, Segotas MC, et al. A pilot study of cognitive behavioral stress management effects on stress, quality of life, and symptoms in persons with chronic fatigue syndrome. J Psychosom Res 2011;70:328-334.

111. Gaab J, Blattler N, Menzi T, Pabst B, Stoyer S, Ehlert U. Randomized controlled evaluation of the effects of cognitive-behavioral stress management on cortisol responses to acute stress in healthy subjects. Psychoneuroendocrinology 2003;28:767-779.

112. Leung SS, Chiang VC, Chui YY, Mak YW, Wong DF. A brief cognitivebehavioral stress management program for secondary school teachers. J Occup Health 2011;53:23-35.

113. Grossman P, Niemann L, Schmidt S, Walach H. Mindfulness-based stress reduction and health benefits. A meta-analysis. J Psychosom Res 2004;57:35-43.

114. Brown KW, Ryan RM. The benefits of being present: mindfulness and its role in psychological well-being. J Pers Soc Psychol 2003;84:822-848.

115. Kabat-Zinn J. Full Catastrophe Living: Using the Wisdom of your Body and Mind to Face Stress, Pain, and Illness. New York: Delta; 1990.

116. Kabat-Zinn J. An outpatient program in behavioral medicine for chronic pain patients based on the practice of mindfulness meditation: theoretical considerations and preliminary results. Gen Hosp Psychiatry 1982;4:33-47.

117. Shapiro SL, Schwartz GE, Bonner G. Effects of mindfulness-based stress reduction on medical and premedical students. J Behav Med 1998; 21:581-599.

118. Chiesa A, Serretti A. Mindfulness-based stress reduction for stress management in healthy people: a review and meta-analysis. J Altern Complement Med 2009;15:593-600.

119. Maslow AH. A theory of human motivation. Psychol Rev 1943;50: 370-396.

120. Antonovsky A. Health, Stress and Coping. Washington DC: JosseyBass Publishers; 1979.
121. Freund KS, Lous J. The effect of preventive consultations on young adults with psychosocial problems: a randomized trial. Health Educ Res 2012;27:927-945.

122. Wainwright NW, Surtees PG, Welch AA, Luben RN, Khaw KT, Bingham SA. Healthy lifestyle choices: could sense of coherence aid health promotion? J Epidemiol Community Health 2007;61:871-876.

123. Seligman ME, Rashid T, Parks AC. Positive psychotherapy. Am Psychol 2006;61:774-788.

124. Frisch MB. Quality of life therapy and assessment in health care. Clin Psychol Sci Pract 1998;5:19.

125. Rodrigue JR. A randomized evaluation of quality of life therapy with patients awaiting lung transplantation. Am J Transplant 2005;5:2425.

126. Fava GA, Tomba E. Increasing psychological well-being and resilience by psychotherapeutic methods. J Pers 2009;77:1903-1934.

127. Ryff CD. Happiness is everything, or is it? Explorations on the meaning of psychological well-being. J Pers Soc Psychol 1989;57:1069.

128. Seligman MEP. Positive psychology progress: empirical validation of interventions. Am Psychol 2005;60:410.

129. Rutter M. Psychosocial resilience and protective mechanisms. Am J Orthopsychiatry 1987;57:316-331.

130. Hoge EA, Austin ED, Pollack MH. Resilience: research evidence and conceptual considerations for posttraumatic stress disorder. Depress Anxiety 2007;24:139-152.

131. Luthar SS, Zigler E. Vulnerability and competence: a review of research on resilience in childhood. Am J Orthopsychiatry 1991;61:6-22.

132. Ai AL, Cascio T, Santangelo LK, Evans-Campbell T. Hope, meaning, and growth following the September 11, 2001, terrorist attacks. J Interpers Violence 2005;20:523-548.

133. Garmezy N. Children in poverty: resilience despite risk. Psychiatry 1993;56:127-136.

134. Kulis S, Hodge DR, Ayers SL, Brown EF, Marsiglia FF. Spirituality and Religion: Intertwined Protective Factors for Substance Use among Urban American Indian Youth. Am J Drug Alcohol Abuse 2012;38:444449.

135. Lamba G, Ellison JM. Religion/Spirituality and depression. Am J Psychiatry 2012;169:433.

136. Southwick SM, Vythilingam M, Charney DS. The psychobiology of depression and resilience to stress: implications for prevention and treatment. Annu Rev Clin Psychol 2005;1:255-291.

137. Jorm AF. Mental health literacy. Public knowledge and beliefs about mental disorders. Br J Psychiatry 2000;177:396-401.

138. Churchill R. No health without mental health: A role for the cochrane collaboration. Cochrane Database Syst Rev 2010;2011:ED000012. 